\title{
The Reaction of Pyridinecarboxylic Acids with Dicyclohexylcarbodiimide and $p$-Nitrophenol
}

\author{
Anders Ljungqvist and Karl Folkers \\ Institute for Biomedical Research, The University of Texas at Austin, Austin, TX78712, USA
}

Ljungqvist, A. and Folkers, K., 1988. The Reaction of Pyridinecarboxylic Acids with Dicyclohexylcarbodiimide and $p$-Nitrophenol. - Acta Chem. Scand., Ser. B 42: 408-410

To modify the terminal amino groups of lysine and ornithine, we recently needed the $p$-nitrophenyl esters of 2-pyridinecarboxylic (picolinic) acid, 3-pyridinecarboxylic (nicotinic) acid and 4pyridinecarboxylic (isonicotinic) acid. We used the method described by Bodanszky and du Vigneaud $^{2}$ for the preparation of benzyloxycarbonylasparagine and glutamine $p$-nitrophenyl ester. Their method consists of adding dicyclohexylcarbodiimide (DCC) to a solution of the acid and a $20 \%$ excess of $p$-nitrophenol in $N, N$-dimethylformamide (DMF). The results were satisfactory in the case of nicotinic and isonicotinic acid, and the corresponding esters were obtained in a yield of about $60 \%$ after recrystallization.

In the case of picolinic acid (1), however, this procedure was not satisfactory and two major products were formed which could be isolated by fractional crystallization from 2-propanol. $p$-Nitrophenyl picolinate (2) was the minor product, isolated in a yield of only $16 \%$. The major product, isolated in a yield of $32 \%$, was $N$-picolinoyl$N, N^{\prime}$-dicyclohexylurea (3). When the reaction was carried out in dichloromethane, the desired ester was obtained in a yield of $70 \%$ after recrystallization. Only a minor amount of acylurea was formed in this solvent. This is in accordance with results obtained with methods using chloroform ${ }^{3}$ and pyridine ${ }^{4}$ as solvents.

The activation of carboxylic acids by DCC is generally thought to proceed as originally proposed by Khorana. ${ }^{5}$ The intermediate is presumed to be a $N, N^{\prime}$-dicyclohexyl- $O$-acylisourea which can acylate the substrate directly or react with a second molecule of the acid to give an anhydride and dicyclohexylurea (DCU). The side reaction is an intramolecular $\mathrm{O} \rightarrow \mathrm{N}$ acyl shift to yield an $\mathrm{N}$-acylurea.

In the peptide field, DCC-mediated couplings have been studied extensively, and $\mathrm{O} \rightarrow \mathrm{N}$ acyl transfer has been traditionally considered to be promoted by high temperatures ${ }^{6,7}$ or by bases such as amines, ${ }^{6,8}$ especially when present in excess, ${ }^{9}$ and the use of polar solvents such as THF $^{10,11}$ and dioxane. ${ }^{11}$ Sterically hindered amino acids such as Val or Ile show a pronounced tendency to rearrange due to a slow reaction with a nucleophile. ${ }^{12}$

In our synthesis, high yields of acylurea were formed only in DMF and only with picolinic acid. Both the solvent and the structure of the acid influence the reaction. Possible reaction mechanisms are shown in Scheme 1. In dichloromethane, picolinic acid (1) may react in the normal way, perhaps via an ion pair, as favoured by DeTar and Silverstein ${ }^{13}$ for acetic acid, to form the $O$-acylisourea (4). Compound 4 may then acylate $p$-nitrophenol or react with a second molecule of the acid to give anhydride and DCU.

In DMF, the reaction may be different from that in dichloromethane. In the polar solvent DMF, picolinic acid may exist to a substantial degree as the zwitterion (1a), as is the case for all pyridinecarboxylic acids in aqueous solution. ${ }^{14}$ The zwitterion may react with DCC to form the adduct 5 , which is stabilized by intramolecular hydrogen bonding. This adduct may have a lifetime sufficient to allow it to rearrange to the $\mathrm{N}$-acylurea (3). It is plausible to have a negative charge on the DCC nitrogen atoms since bases have been shown to increase the formation of $\mathrm{N}$-acylurea. 

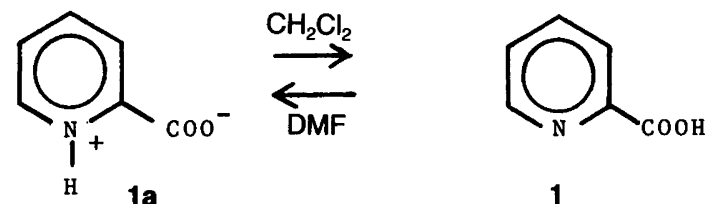

$\operatorname{scc} \mid$

1<smiles></smiles><smiles>[R10]C1OC(=O)c2cccc[n+]2[NH+]([R])[C@H]1[R]</smiles><smiles>[R]N1[Y]2ccccc2C(=O)OC1=[Y10]</smiles>

5

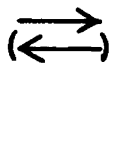

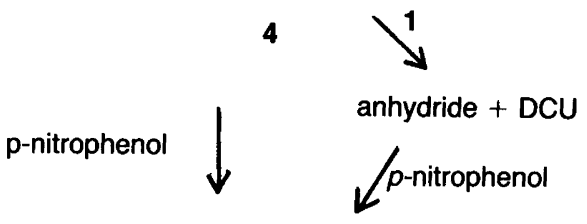<smiles>[R]NC(=O)N([R])C(=O)c1ccccn1</smiles>

3

Scheme 1. R = cyclohexyl.

Support for this reaction scheme is provided by a report by Arendt and Kolodziejczyk ${ }^{15}$ on the reaction between $N$-formylphenylalanine and DCC. They suggested that the isomeric acylureas are formed in parallel reactions, and that, consequently, $\mathrm{N}$-acylurea is not formed via $\mathrm{O}$-acylisourea. In this context, $N, N$-dimethylglycine hydrochloride was reported to react with DCC in ethanol to give a high yield of the ethyl ester; however, the free acid, which most likely exists as the zwitterion in ethanol, gives $\mathrm{N}$-acylurea. ${ }^{16}$

There are other mechanistic alternatives, and the most obvious one is that in DMF, but not in dichloromethane, the transformation $\mathbf{4} \rightarrow \mathbf{5}$ is reasonably fast compared to reaction with a nucleophile. This alternative seems less likely, because 4 should react rapidly with $p$-nitrophenol as proposed by DeTar and Silverstein ${ }^{13}$ for the corre- sponding reaction with acetic acid. The possibility of intramolecular base catalysis by the pyridine nitrogen could further facilitate ester formation. We have observed that acylation of the $\varepsilon$-amino group of BOC-lysine with $p$-nitrophenyl picolinate in DMF is substantially faster than acylation with the isomeric nicotinic and isonicotinic esters. ${ }^{17}$

\section{Experimental}

Melting points were measured on a Thomas Hoover capillary melting point apparatus and are uncorrected. NMR data are reported as $\delta$-values downfield from TMS.

General procedure for esterification. ${ }^{2}$ Acid $(10 \mathrm{~g}$, $81 \mathrm{mmol})$ and $p$-nitrophenol $(13.4 \mathrm{~g}, 96 \mathrm{mmol})$ 
were dissolved/suspended in $250 \mathrm{ml}$ of DMF (with ice-cooling for nicotinic and picolinic acids). $16.7 \mathrm{~g}(81 \mathrm{mmol})$ of DCC were then added and stirring was continued for $4 \mathrm{~h}$ (after $1 \mathrm{~h}$ at $0{ }^{\circ} \mathrm{C}$ for nicotinic and picolinic acid). The mixture was filtered, the filter cake was washed with $50 \mathrm{ml}$ of cold DMF, and the product was precipitated from the combined filtrate and washings by the addition of $300 \mathrm{ml}$ of water. Filtration and drying in vacuo gave the crude product.

Purification. The esters of nicotinic and isonicotinic acids were purified by recrystallization from 2-propanol. The yield of $p$-nitrophenyl nicotinate was $11.3 \mathrm{~g}, 57 \%$; m.p. $172-173^{\circ} \mathrm{C}$, lit. ${ }^{18} 172^{\circ} \mathrm{C}$. The yield of $p$-nitrophenyl isonicotinate was $12.1 \mathrm{~g}, 61 \%$; m.p. $139-141^{\circ} \mathrm{C}$, lit. ${ }^{3} 137-139^{\circ} \mathrm{C}$.

The crude product from the reaction of picolinic acid was dissolved in $250 \mathrm{ml}$ of hot 2-propanol and the solution was kept in a refrigerator overnight. The precipitated product was redissolved in $170 \mathrm{ml}$ of hot 2-propanol. The ester precipitated from this solution while it was still quite warm, and was isolated by filtration. Two more recrystallizations gave $3.15 \mathrm{~g}, 15.8 \%$, of pure $p$-nitrophenyl picolinate; m.p. $155-157^{\circ} \mathrm{C}$ (decomp.), lit. ${ }^{4} 144-146^{\circ} \mathrm{C}$ (decomp.). We consistently observed melting points of about $155^{\circ} \mathrm{C}$. NMR $\left(\mathrm{CDCl}_{3}\right), 200 \mathrm{MHz}: \delta 7.48$ and $8.34, \mathrm{~m}, 2 \mathrm{H}$ each, $\mathbf{A A}^{\prime} \mathbf{B B}^{\prime}$ pattern from the nitrophenyl group; 7.62, eight lines, $1 \mathrm{H}$, pyridine $\mathrm{H}^{5}, J_{5,4}=$ $8 \mathrm{~Hz}, J_{5,6}=5 \mathrm{~Hz}, J_{5,3}=1.5 \mathrm{~Hz} ; 7.97$, six lines, $1 \mathrm{H}$, pyridine $\mathrm{H}^{4}, J_{4,5}=J_{4,3}=8 \mathrm{~Hz}, J_{4,6}=1.8 \mathrm{~Hz}$; 8.30 , m. $1 \mathrm{H}$, pyridine $\mathrm{H}^{3}, J_{3,4}=8 \mathrm{~Hz}, J_{3,5}<1 \mathrm{~Hz}$; 8.87 , m. $1 \mathrm{H}$, pyridine $\mathrm{H}^{6}, J_{6,5}=5 \mathrm{~Hz}$. Anal. $\mathrm{C}_{12} \mathrm{H}_{8} \mathrm{~N}_{2} \mathrm{O}_{4}: \mathrm{C}, \mathrm{H}, \mathrm{N}$.

The mother liquor from the $170 \mathrm{ml}$ of solution was evaporated to give $11 \mathrm{~g}$ of crude acylurea. Recrystallization from $50 \mathrm{ml}$ of 2-propanol gave $8.5 \mathrm{~g}, 32 \%$, of pure $N$-picolinoyl- $N, N^{\prime}$-dicyclo-

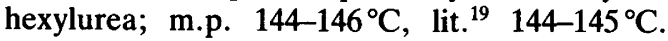
NMR $\left(\mathrm{CDCl}_{3}\right), 200 \mathrm{MHz}: \delta 0^{2}-2.0, \mathrm{~m}, 20 \mathrm{H}$, cyclohexyl $\mathrm{CH}_{2}$ groups; $3.52, \mathrm{~m}$, and $4.18, \mathrm{~m}, 1 \mathrm{H}$ each, cyclohexyl $\mathrm{CH}$ groups; 6.02 , broad $\mathrm{d}, 1 \mathrm{H}$, $\mathrm{NH} ; 7.35$, eight lines, $1 \mathrm{H}$, pyridine $\mathrm{H}^{5} ; 7.68$, $\mathrm{m}$, $1 \mathrm{H}$, pyridine $\mathrm{H}^{3} ; 7.79$, six lines, $1 \mathrm{H}$, pyridine $\mathrm{H}^{4}$; $8.57, \mathrm{~m}, 1 \mathrm{H}$, pyridine $\mathrm{H}^{6}$. The values of the coupling constants for the aromatic protons are the same as for the corresponding protons in the ester.
Acknowledgements. Appreciation is expressed to Dr. Marvin Karten, to the Contraceptive Development Branch of the National Institutes of Child Health and Human Development (contract No. NO1-HD-6-2938), and to the Robert A. Welch Foundation for their respective support of this research.

\section{References}

1. Ljungqvist, A., Feng, D.-M., Tang, P.-F. L., Kubota, M., Okamoto, T., Zhang, Y., Bowers, C. Y. and Folkers, K. Biochem. Biophys. Res. Commun. 148 (1987) 849.

2. Bodanszky, M. and du Vigneaud, V.J. Am. Chem. Soc. 81 (1959) 5688.

3. Fife, T. H. and Przystas, T. J. J. Am. Chem. Soc. 107 (1985) 1041.

4. Sigman, D. S. and Jorgensen, C. T. J. Am. Chem. Soc. 94 (1972) 1724.

5. Khorana, H. G. Chem. Ind. (London) (1955) 1087.

6. Helferich, B. and Böshagen, H. Chem. Ber. 92 (1959) 2813.

7. Schneider, F. Hoppe-Seyler's Z. Physiol. Chem. $320(1960) 82$.

8. Schüssler, H. and Zahn, H. Chem. Ber. 95 (1962) 1076.

9. Zahn, H. and Schüssler, H. Liebigs Ann. Chem. 641 (1961) 176.

10. Merrifield, R. B. and Woolley, D.W. J. Am. Chem. Soc. 78 (1956) 4646.

11. Sheehan, J.C., Goodman, M. and Hess, G. P. J. Am. Chem. Soc. 78 (1956) 1367.

12. Izdebski, J., Kubiak, T., Kunce, D. and Drabarek, S. Pol. J. Chem. 52 (1978) 539.

13. DeTar, D. F. and Silverstein, R. J. Am. Chem. Soc. 88 (1966) 1020.

14. Joule, J. A. and Smith, G. F. Heterocyclic Chemistry, Van Nostrand Reinhold, London 1972, p. 67.

15. Arendt, A. and Kolodziejczyk, A. M. Tetrahedron Lett. 40 (1978) 3867.

16. Yurkevich, A.M., Verenikina, S. G., Dolgikh, M.S. and Preborazhenskii, N.A. Zh. Obshch. Khim. 37 (1967) 1267.

17. Ljungqvist, A. Unpublished observations.

18. Zinner, H. and Fiedler, H. Arch. Pharm. 291 (63) (1958) 330.

19. Avramovici-Grisaru, M.S. and Sarel, S. Nouv. J. Chim. 6 (1982) 455.

Received February 25, 1988. 